\title{
UM OLHAR SOBRE SISTEMAS DE SAUDE LOCAIS E NACIONAIS
}

\author{
Juliana Braga de Paula \\ Centro Universitário 7 de Setembro - Fortaleza (CE) - Brasil \\ Centro Universitário UniFanor/ Wyden - UniFanor/WIDEN - Fortaleza (CE) - Brasil \\ Instituto de Ensino e Pesquisa do Hospital Sírio Libanês - São Paulo (SP) - Brasil \\ Flávio Ibiapina \\ Universidade de Fortaleza - UNIFOR - Fortaleza (CE) - Brasil

\section{Philippe Mossé} \\ Laboratoire dĖconomie et de Sociologie du Travail - LEST - Aix Marseille Université - Marseille - France
}

Os Sistemas Universais de Saúde estão em cheque na atual conjuntura global. A crise econômica que abalou as grandes potências, os desafios da estabilidade fiscal, o crescimento exponencial de novas tecnologias e as ameaças às políticas sociais fazem da ideia de manter sistemas públicos e universais um tema polêmico e questionado por muitos governos. Para além dos argumentos inevitáveis da importância de um sistema público e gratuito para a saúde dos povos, existem evidências de que um sistema de saúde organizado seja um grande investimento para qualquer país, considerando, por exemplo, os complexos industriais nacionais, a redução de internações de alta complexidade e a diminuição do gasto público com medicamentos e equipamentos de alta tecnologia. Na saúde global, observam-se tentativas de reconstrução de sistemas de saúde que se adequem ao avanço dessas tecnologias médicas e inovações de serviços que aumentem o desempenho do sistema, ao mesmo tempo em que mantenham as populações mais vulneráveis no campo de prioridades de ação dos governos.

Cada vez mais, há uma preocupação constante para que esses sistemas diminuam desperdício, aumentem a efetividade e respondam às necessidades dos usuários e dos governos com qualidade e prontidão. Pesquisadores e governos têm criado, há processos e ferramentas que contribuem para a melhoria de sua resposta às necessidades de saúde, como as estratégias de governança clínica, controle de qualidade e a avaliação de desempenho propriamente dita.

A ideia de um sistema de saúde universal e abrangente nasce no pós-guerra com a ascensão dos Estados de Bem-Estar Social. Quando se trabalha com modelos de estados protetores tem-se muitas tipologias disponíveis ${ }^{(1,2)}$, mas as duas mais emblemáticas são o modelo Beveridge e Bismarck ${ }^{(3)}$. A diferença fundamental entre esses dois modelos está relacionada ao papel que a burocracia estatal desempenha na coordenação e na elaboração de políticas. No chamado desenho Beveridgiano, o Estado é um ator chave no financiamento, na elaboração de políticas, regulação, organização e governança. No modelo Bismarkiano, o Estado atua fundamentalmente como uma referência e os atores chaves seriam os sindicatos e as corporações.

Entre os anos 50 até os anos 80 , dos pontos de vista econômicos e de saúde pública, os modelos de seguridade social mais protetores foram considerados de grande sucesso. A qualidade aumentou e o acesso aos seguros de saúde e aos cuidados aumentaram, como no caso Francês, onde as pessoas estavam orgulhosas do seu seguro social de saúde, saindo de $5 \%$ nos anos 60 para mais de $10 \%$ nos anos 80 ; e os sistemas Inglês e Canadense, que se transformaram em representação da identidade social de seus países ${ }^{(3)}$.

De um ponto de vista macroeconômico, essa era foi chamada de "Anos Gloriosos", se referindo a um crescimento econômico e social reconhecido por quase todo o mundo ocidental. No entanto, do ponto de vista da regulação, o cenário era menos glorioso, pois persistiam grandes iniquidades entre países e dentro dos países, entre populações com baixa e alta renda ${ }^{(3)}$. 
Até os anos $70^{(4)}$, o principal objetivo do planejamento das políticas de saúde era sustentar o crescimento econômico. Ademais, em uma perspectiva macroeconômica, o crescimento era uma boa forma de se evitar de ter que fazer escolhas ou estabelecer prioridades, prevenindo os conflitos dentro do próprio sistema; dessa forma, era permitido o desperdício de recursos. No Sistema Fordista, cada política de saúde era considerada como investimento no capital humano. Políticas desse tipo eram caras porque inflacionavam a demanda e geravam um grande déficit público, mas à época, ninguém dava real atenção.

Nos anos $80^{(5)}$, com os governos Thatcher e Reagan e a ascensão do neoliberalismo e da globalização, as políticas Keynesianas falharam e os países iniciaram uma série de reformas e adaptações, muito relacionadas às críticas quanto à efetividade, à eficiência e ao desempenho inadequado dos serviços de saúde.

A avaliação de desempenho tem sido amplamente discutida nos países com sistemas de saúde mais maduros e existe uma clara tensão entre garantir a integralidade do sistema e, ao mesmo tempo, garantir que as ações sejam implementadas, considerando a equidade. Para os especialistas, as ferramentas de avaliação de desempenho não respondem por si só às transformações requeridas, há que se articular todo um aparato de universidades, governos e sociedades para que as ferramentas estejam a serviço das necessidades da população e não à margem delas.

Considera-se, ainda, importante o debate sobre os países que ainda não atingiram a universalidade, uma vez que a governança da boa performance com equidade torna-se mais desafiador, principalmente em momentos de crise e de políticas austeras, considerando que esses países ainda se deparem com a tarefa de ampliação de cobertura. A crise econômica que se abateu sobre o mundo em 2008 fez com que a visão de um sistema abrangente fosse questionada, mas já existem exemplos de países europeus como Portugal que optaram por manter o seu sistema funcionando e tem dado bons resultados. Por outro lado, observam-se contingenciamentos nos sistemas Canadenses e Inglês, como demonstram os artigos desse número especial( ${ }^{(6,7)}$.

A América Latina ${ }^{(8)}$, em sua maioria, nem chegou a desenvolver um sistema universalista, com exceção do Brasil, que a partir de 1988, aprovou um modelo constitucional universal, compreensivo e participativo. O Brasil, como os países da América Latina, tem procurado achar respostas para os problemas do seu sistema de saúde, mas a troca de experiências e o bom debate são estratégias importantes para que a sociedade possa se posicionar sobre qual tipo de sistema ela quer construir, quais respostas precisam ser dadas pelos serviços e qual a melhor forma de acesso e de comunicação da sociedade com os governos, para que se garanta um serviço de saúde cada vez mais centrado no cidadão.

Considerando a relevância do tema, a Comissão de Seguridade Social e Família, do Governo Federal, apoiou o "Fórum Internacional de Sistemas Universais de Saúde: Lançando olhar sobre o desempenho de serviços de saúde locais e nacionais". A partir das discussões levantadas nesse fórum, a comissão científica do mesmo organizou esse número especial para ser publicado na Revista Brasileira em Promoção da Saúde, com convidados de universidades e pesquisadores internacionais, em parceria com a Universidade de Fortaleza, com o objetivo de disseminar o debate entre estudiosos e sociedade civil.

Temas como o processo de descentralização, problemas com desigualdades sociais, subfinanciamento e organização de serviços fizeram com que o desenho e a governança do sistema fossem questionados, abrindo espaço para novos agenciamentos como as Organizações Sociais e Contratos Organizativos de Ação Pública ${ }^{(9)}$. Outro problema apontado como fundamental para a sobrevivência de sistemas integrais de saúde são as políticas de recursos humanos, as dificuldades com a corporação médica e a formação de profissionais ${ }^{(10,11)}$. O financiamento e os determinantes sociais da saúde são ainda discutidos ${ }^{(6,9,12)}$ analisando-se o financiamento sob uma perspectiva internacional, comparando-se sistemas maduros, e então, com uma análise das implicações para o financiamento público da tentativa de regionalização dos serviços no Estado de São Paulo, por exemplo.

Com isso, pretende-se fazer um bom debate sobre estratégias e ferramentas de avaliação, esperando contribuir com o aumentar da qualidade do sistema de saúde brasileiro, ampliando sua cobertura para quem mais precisa e organizando experiências no campo nacional, além de colaborar, posteriormente, com a sistematização e a difusão no território brasileiro de ações exitosas.

\section{REFERÊNCIAS}

1. Hall P, Soskice D. Varieties of capitalism: The Institutional Foundations of comparative advantage. New York: Oxford Press; 2003.

2. Esping-Andersen G. Social foundations of postindustrial economies. New York: Oxford Univ. Press; 1999. 
3. Mossé P. Bismarck et Beveridge: des protoptypes aux archétypes. Après Demain. 2017;42:12-4.

4. Knight B. Beveridge at 70. Newcastle: Webb Memorial Trust; 2002.

5. Nay O, Béjean S, Benamouzig D, Bergeron H, Castel P, Ventelou B. Achieving universal health coverage in France: policy reforms and the challenge of inequalities. Lancet. 2016;387:2236-49.

6. Ferreira MRJ, Mendes NA. Reformas nos sistemas de saúde alemão, francês e britânico. Rev Bras Promoç Saúde [Internet]. 2018 [acesso em 01 Dez 18]; 31(4)1-10. Disponível em: http://periodicos.unifor.br/RBPS/article/ view/8775

7. Denis JL, Usher S, Preval J, Côté-Boileau E. Health system reforms in mature welfare states: tales from the North. Rev Bras Promoç Saúde [Internet]. 2018 [acesso em 02 Dez 18]; 31(4)1-15. Disponível em: http://periodicos. unifor.br/RBPS/article/view/8802

8. Coniil EM. Sistemas universais para a América Latina: jovens e antigas inovações nos serviços de saúde. Rev Bras Promoç Saúde [Internet]. 2018 [acesso em 01 Dez 18]; 31(4)1-13. Disponível em: http://periodicos.unifor. br/RBPS/article/view/8779

9. Goya N, Andrade LOM. O sistema único de saúde e o desafio da gestão regionalizada e contratualizada. Rev Bras Promoç Saúde [Internet]. 2018 [acesso em 02 Dez 18]; 31(4)1-10. Disponível em: http://periodicos.unifor. $\mathrm{br} /$ RBPS/article/view/8773

10. Paula JB, Westphal MF. Sistemas de saúde, cooperação horizontal e o Programa Mais Médicos no Brasil. Rev Bras Promoç Saúde [Internet]. 2018 [acesso em 01 Dez 18]; 31(4)1-9. Disponível em: http://periodicos.unifor. br/RBPS/article/view/8780

11. Evangelista ALP, Frota AC, Torres RBS, Barreto ICHC. Residência Integrada em Saúde Mental: cuidado à rede de atenção psicossocial. Rev Bras Promoç Saúde [Internet]. 2018 [acesso em 01 Dez 18]; 31(4)1-11. Disponível em: http://periodicos.unifor.br/RBPS/article/view/8774

12. Ribeiro KG, Aguiar JB, Andrade LOM. Determinantes sociais da saúde: o instituído constitucional no sistema Único de Saúde. Rev Bras Promoç Saúde [Internet]. 2018 [acesso em 01 Dez 18]; 31(4)1-10. Disponível em:

\section{Endereço para correspondência:}

Juliana Braga de Paula

Centro Universitário 7 de Setembro

Av. Almirante Maximiniano da Fonseca, 1395

Bairro: Engenheiro Luciano Cavalcante

CEP : 60811-020 - Fortaleza - CE - Brasil

E-mail: julianadepaula5@gmail.com 